\title{
Threefold increased risk of hip fractures with rheumatoid arthritis in Central Finland
}

\author{
T M Huusko, M Korpela, P Karppi, V Avikainen, H Kautiainen, R Sulkava
}

Department of
Rehabilitation,
Division of Geriatrics,
Central Hospital of
Central Finland,
Jyväskylä, Finland
T M Huusko
P Karppi
Department of
Surgery, Division of
Orthopaedic and
Trauma Surgery,
Central Hospital of
Central Finland,
Jyväskylä, Finland
V Avikainen
Department of
Internal Medicine,
Section of
Rheumatology,
Tampere University
Hospital, Pikonlinna,
Finland
M Korpela
Rheumatism
Foundation Hospital,
Heinola, Finland
H Kautiainen
Department of Public
Health and General
Practice, Division of
Geriatrics, University
of Kuopio, Kuopio,
Finland
R Sulkava
Correspondence to:
Dr T M Huusko,
Puolarmetsö Hospital,
Puolarinportti 1,02290
Espoo, Finland
tiina.huusko@espoo.fi
Accepted 26 September
2000

Department of

Rehabilitation Central Hospital of

Central Finland

T M Huusko

P Karppi

Department of Surgery, Division of Central Hospital of Central Finland, V Avikainen

Department of Section of

Rheumatology, Hospital, Pikonlinna, Finland

Foundation Hospital, Heinola, Finland

Department of Public Health and General Geriatrics, University of Kuopio, Kuopio Finland

Correspondence to: Dr T M Huusko,

Puolarmetsö Hospital, Espoo, Finland

Accepted 26 September

\begin{abstract}
Objectives-To evaluate the impact of rheumatoid arthritis (RA) on the incidence of hip fractures.

Methods-All patients with acute hip fractures admitted to Jyväskylä Central Hospital in 1991-93 $(n=517)$ were selected from the hospital discharge register. Medical records of these patients were studied retrospectively for $\mathrm{RA}$ fulfilling the American Rheumatism Association criteria. The prevalence of RA in patients with hip fractures was compared with the prevalence rates of RA obtained from the nearby city of Tampere.

Results-29 (5.6\%; 95\% CI 3.8 to 8.0$)$ of the patients with hip fracture in Jyväskylä Central Hospital had RA. The age and sex adjusted risk of hip fractures was increased by RA (risk ratio 3.26; 95\% CI 2.26 to 4.70 ).
\end{abstract}

Conclusions-Patients with RA are at increased risk of osteoporotic hip fractures.

(Ann Rheum Dis 2001;60:521-522)

Several separate health disorders have been related to increased risk of hip fractures in the elderly. The relative risk for hip fractures in patients with rheumatoid arthritis (RA) has been reported to be $1.5^{1}$ and $2.1 .^{2}$ In Finland it has been estimated that the number of excess deaths related to the presence of RA is $400-450$ a year. ${ }^{3}$ Five of these excess deaths were attributed to osteoporotic fractures.

The purpose of this study was to evaluate the significance of RA as a risk factor for hip fractures in the province of Central Finland during 1991-93.

\section{Patients and methods}

Five per cent of the population of Finland lives within the Central Finland Health Care District. In Finland there is a consensus that all patients with acute hip fractures be referred to

Table 1 Prevalence of rheumatoid arthritis $(R A)$ in patients with hip fracture in Central Finland in 1991-93 and in the general population in Tampere 1987

\begin{tabular}{|c|c|c|c|c|c|}
\hline \multirow[b]{2}{*}{ Sex and age } & \multicolumn{2}{|c|}{ Patients with hip fracture } & \multicolumn{2}{|l|}{ Population } & \multirow[b]{2}{*}{$\begin{array}{l}\text { Relative risk } \\
(95 \% \text { CI) }\end{array}$} \\
\hline & $\begin{array}{l}\text { Patients with } \\
R A \\
\text { No (\%) }\end{array}$ & $\begin{array}{l}\text { Total number } \\
\text { of patients }\end{array}$ & $\begin{array}{l}\text { Patients with } \\
R A \\
\text { No (\%) }\end{array}$ & $\begin{array}{l}\text { Total number } \\
\text { of subjects }\end{array}$ & \\
\hline \multicolumn{6}{|l|}{ Women: } \\
\hline$\leqslant 64$ & $2(9)$ & 22 & $447(0.7)$ & 61334 & 12.5 (3.3 to 46.9$)$ \\
\hline $65-84$ & $18(8)$ & 234 & $368(2.5)$ & 14917 & $3.1(2.0$ to 4.9$)$ \\
\hline$\geqslant 85$ & $3(3)$ & 117 & $19(1.5)$ & 1300 & $1.8(0.5$ to 5.8$)$ \\
\hline \multicolumn{6}{|l|}{ Men: } \\
\hline$\leqslant 64$ & $1(4)$ & 27 & $134(0.2)$ & 57515 & $15.9(2.3$ to 109.6$)$ \\
\hline $65-84$ & $3(3)$ & 88 & $81(1.2)$ & 6992 & $2.9(0.9$ to 9.1$)$ \\
\hline$\geqslant 85$ & $2(7)$ & 29 & $2(0.7)$ & 285 & $9.8(1.4$ to 67.2$)$ \\
\hline
\end{tabular}

Age and sex adjusted Mantel-Haenszel rate ratio 3.26 (95\% CI 2.26 to 4.70). hospital for surgical assessment and treatment. Jyväskylä Central Hospital is the only place for referral to specialist care in this area, except in three small municipalities in the southern part of the province where the patients are partly treated in a local hospital. Those three municipalities were excluded from this study.

The mean population was calculated using data obtained from the registers of the Social Insurance Institution of Finland. The mean population of the study area was 231697.

Patients with acute hip fractures admitted to Jyväskylä Central Hospital between January 1991 and December 1993 were selected from the hospital discharge register. To verify that no patients had accidentally been overlooked, contemporaneous records from the Department of Anaesthesiology and a hand written record of patients with hip fracture held in the traumatology ward were studied. Medical records of these patients were studied retrospectively by a specialist in internal medicine for definite or classical RA according to the American Rheumatism Association (ARA) 1958 criteria. $^{4}$

The sex and age specific prevalence rates of RA among patients with hip fracture in Central Finland were compared with the rates obtained from a population based study in the city of Tampere (population 170 511) in $1987 . .^{5}$ In Tampere the doctors' certificates of all those aged 15 years or more admitted to the special reimbursement category by the Sickness Insurance Register because of RA and allied conditions were re-evaluated by a rheumatologist using a standard protocol for the ARA criteria. All patients with definite or classical RA were studied prospectively or retrospectively and all cases with incorrect classification of the joint disease were excluded. The sex and age distributions of the population of Tampere were obtained from the official population statistics.

Mantel-Haenzel test, Student's $t$ test, and the $\chi^{2}$ test were used for statistical testing.

\section{Results}

A total of 517 patients with acute hip fractures (373 (72\%) women, 144 (28\%) men) were admitted to Jyväskylä Central Hospital between 1991 and 1993. The mean age of the patients was 78 (range 15-99). Men were significantly younger (mean age 74 ) than women (mean age $80, \mathrm{p}<0.0001$ ).

Twenty nine patients with hip fractures admitted to Jyväskylä Central Hospital had definite or classical RA $(5.6 \% ; 95 \%$ CI 3.8 to 8.0 ). Table 1 shows the prevalence of RA in patients with hip fractures in Central Finland and in the general population in the city of Tampere. ${ }^{5}$ The age and sex adjusted MantelHaenzel risk ratio for hip fractures in the 
patients with RA was 3.26 (95\%; CI 2.26 to 4.70). The relative risk was highest in the group aged $\leqslant 64$.

The mean age of the RA patients with hip fractures was 77 (range 52-91) for women and 79 (range 62-92) for men. The corresponding figures for the patients with hip fracture and no RA were 80 (range 41-99) for women and 74 (range 15-93) for men.

There were $15(52 \%)$ cervical hip fractures and $14(48 \%)$ trochanteric fractures among the patients with RA. The corresponding figures for patients who did not have RA were 315 $(65 \%)$ for cervical fractures and $173(35 \%)$ for trochanteric fractures $(\mathrm{p}=0.163)$.

\section{Discussion}

In Finland all patients with acute hip fractures are referred to hospital for surgical assessment and treatment. The only hospital for referral in this area with a population of 231697 is Jyväskylä Central Hospital. Although retrospective, this study should give reliable incidence rates for hip fractures.

The diagnoses of RA were made using the medical records of Jyväskylä Central Hospital according to the ARA criteria. Jyväskylä Central Hospital is the only specialist referral centre for RA in the area. Most patients with RA should be found by this method because a certificate of a specialist is needed for the special reimbursement of drugs.

Tampere lies only 151 kilometres from Jyväskylä. The morbidity, diagnostic criteria, and treatment of RA are supposed not to be different from those of the Jyväskylä area. In the Mini Finland Health Survey ${ }^{6}$ no significant differences were found in the prevalence of locomotor diseases between different parts of Finland.

A consistent $1 \%$ overall prevalence for definite or classic RA has been reported among different countries and races. In the present study $29 / 517(5.6 \%)$ of patients with hip fracture had RA. It was a significant risk factor for hip fractures in men and in women. The relative risk was highest in the age group of 64 or younger. Physical impairment and corticosteroids have been related with osteoporosis and increased risk of hip fractures ${ }^{1-9}$ among patients with RA.

In this study RA was a more important risk factor for hip fractures than in earlier reports from the United Kingdom and the USA. ${ }^{12}$ In the study in Southampton General Hospital ${ }^{2}$ the relative risk for hip fractures in patients with RA was 2.1. The rate of response among controls was, however, only $71 \%$, which may partly be responsible for the difference in the results. In Rochester, Minnesota ${ }^{1}$ the relative risk was 1.5 . In this study a cohort of female residents with RA diagnosed during 1950-74 was investigated in 1983. Patients with possible RA were included in the study.

We conclude that there is a threefold increased risk of hip fractures for those with RA in Central Finland.

Sources of support: University of Kuopio and Central Finland Health Care District.

1 Hooyman JR, Melton LJ, Nelson AM, O'Fallon WM, Riggs BL. Fractures after rheumatoid arthritis. A population based study. Arthritis Rheum 1984;27:1353-61.

2 Cooper C, Coupland C, Mitchell M. Rheumatoid arthritis, corticosteroid therapy and hip fracture. Ann Rheum Dis 1995;54:49-52.

3 Myllykangas-Luosujärvi RA, Aho K, Isomäki H. Mortality in rheumatoid arthritis. Semin Arthritis Rheum 1995;25: 193-202.

4 Ropes MW, Bennett GA, Cobb S, Jacox R, Jesser RA. 1958 revision of diagnostic criteria for rheumatoid arthritis. Bull revision of diagnostic criteria
Rheum Dis 1958;9:175-6.

5 Korpela M. Rheumatoid arthritis and the kidneys. A crosssectional study on the prevalence, clinical significance and risk of renal and urinary tract diseases in patients with rheumatoid arthritis. The Social Insurance Institution of Finland 1993;ML 122:210.

6 Aromaa A, Heliövaara M, Impivaara O, Knekt P, Maatela J, Joukamaa $M$, et al. Health, functional limitations and need for care in Finland. Basic results from the Mini-Finland Health Survey. The Social Insurance Institution of Finland 1989.

7 Michel BA, Bloch DA, Fries JF. Predictors of fractures in early rheumatoid arthritis. J Rheumatol 1991;18:804-8. 8 Michel BA, Bloch DA, Wolfe F, Fries J. Fractures in factors. J Rheumatol 1993;20:1666-9.

9 Kröger H, Honkanen R, Saarikoski S, Alhava E. Decreased axial bone mineral density in perimenopausal women with cheumatoid arthritis - a population based study. Ann Rheum Dis 1994;53:18-23. 